\section{A INTERFACE MÚSICA E PSICOLOGIA: UMA PERSPECTIVA HISTÓRICO-ANALÍTICA}

\section{Luiz César Marques Magalhães ${ }^{1}$}

RESUMO: Este artigo analisa a interface música e psicologia a partir da segunda metade do século XIX, identificando e discutindo áreas de interesse, problemas e pesquisas em comum. Os resultados da pesquisa foram organizados em torno de três eixos de análise: razão, subjetividade e psicotécnicas. Construído em torno destes eixos, o texto apresenta uma perspectiva histórico-analítica que permite uma melhor compreensão do estágio atual de desenvolvimento da psicologia da música e as suas ramificaçóes, bem como das dificuldades presentes no desenvolvimento de modelos, testes e avaliaçóes na área de Música, em particular sobre inteligência musical.

PALAVRAS-CHAVE: Psicologia da Música; Educação Musical; Musicologia; Cognição.

THE INTERFACE BETWEEN MUSIC AND PSYCHOLOGY: AN HISTORICAL-ANALYTICAL PERSPECTIVE

ABSTRACT: This article analyzes the interface psychology and music since the second half of 19th century, identifying and discussing shared interests, issues and researches. The findings were organized in three analytical axes: reason, unconscious and psychotechniques. Structured around these axes, the text presents a historical-analytical perspective that allows a better understanding of the current stage of development of the psychology of music and its branches, as well as the difficulties present in the development of models, tests and evaluations in the field of music, particularly musical intelligence.

KEYWORDS: Psychology of Music; Musical Education; Musicology, Cognition.
1. Escola de Música da Universidade Federal da Bahia (UFBA). Email: luizmaga@ufba.br 
2. It may be said that Romanticism represents the period of an apparent domination of instinct over reason, of imagination over form, of heart over head, of Dionysios over Apollo. It sprang from the desire to assert instinctual needs which had been too far suppressed in the Enlightenment and which developed when the claim of rationalism that Man was capable of solving his problems by the exercise of reason was shown to have left too much out of account. (WARRAK, 1980, p.141)

\section{INTRODUÇÃO}

Música e psicologia compartilham não apenas a psicologia da música, disciplina nascida sob a influência do positivismo e da "psicologia científica" do século XIX, mas também atores, conceitos e teorias. Tendo em vista a dimensão do tema, procurou-se construir um texto onde o objetivo principal é fornecer uma visão estrutural do todo e não o aprofundamento nas singularidades dos eventos. Os resultados da pesquisa foram organizados em torno de três eixos de análise: razáo, subjetividade e psicotécnicas. Esta estratégia favoreceu uma perspectiva histórico-analítica que permitirá uma melhor compreensão do estágio atual de desenvolvimento da psicologia da música, bem como das dificuldades presentes no desenvolvimento de modelos, testes e avaliaçóes na área de música.

Olhar através de um binóculo é muito diferente do que através de um microscópio. O olhar distanciado enxerga melhor o contexto, porém sacrifica a percepção dos detalhes. Ao assumir uma perspectiva mais ampla, este artigo náo contempla inúmeros autores e publicaçóes importantes à área em estudo, especialmente a relevante produção científica de autores brasileiros que tem aumentado muito nas últimas décadas, mas contempla seu objetivo principal de estimular o aprofundamento dos debates e a produção de conhecimentos.

Se o ponto de partida adotado fosse exclusivamente a música, um dos eixos de análise poderia ser o surgimento da grafia musical no ocidente e a consequente fixação do gesto musical, ambas diretamente associadas à escolástica e ao culto das doutrinas e virtudes do espírito. Um segundo momento poderia ser o surgimento da polifonia na escola franco-flamenga e o consequente desenvolvimento do contraponto e da harmonia, período que coincide com o surgimento da perspectiva e do novo paradigma científico na renascença. Ou ainda o surgimento do romantismo na música, "período de aparente domínio do instinto sobre a razão, da imaginação sobre a forma, do coração sobre a mente, de Dionísio sobre Apolo"2 (WARRAK, 1980, p. 141). Mas nestes, a psicologia ainda não havia se estabelecido como ciência. A filosofia e, em alguns aspectos, a religião estavam mais próximas do que hoje entendemos por psicologia. Foi durante o século XIX, com o estabelecimento de cadeiras de psicologia nas universidades 
europeias, que pesquisadores de ambas as áreas começaram a constituir os laboratórios e a estudar temas de interesse comum. Segundo L. Figueiredo (2008), a psicologia não pode ser entendida como uma totalidade contínua, mas sim como um arquipélago formado de ilhas distintas com suas próprias teorias, linhas de pensamento, objetos de estudo, métodos de pesquisa, concepções de ser humano. Assim, mais correto seria usar o plural: psicologias, cada uma com suas linhas de estudo, com suas singularidades e projetos. Da mesma forma, poder-se-ia argumentar que náo existe uma única musicologia ou uma única psicologia da música, mas muitas; cada uma com suas histórias, suas teorias, suas práticas.

\section{RAZÃO}

A psicologia encontrou seu espaço no rol das ciências na segunda metade do século XIX. Ela emergiu do complexo processo de industrialização por que passou a Europa, centrada na razáo, na consciência, e na busca da compreensáo dos processos perceptivos e cognitivos. Também surgiu influenciada pela crise da subjetividade que nasceu com a percepçáo de que os seres humanos não são tão livres e iguais quanto a doutrina liberal julgava (CAMBAÚVA et al., 1998).

É significativo como algumas conquistas artísticas ou científicas têm a capacidade de ressoar em diferentes dimensôes do pensamento humano revolucionando paradigmas, conceitos, procedimentos. Tais mudanças, juntamente com as controvérsias que quase sempre as acompanham, são características das revoluçóes científicas. Em determinados momentos, uma nova teoria, um novo conhecimento, uma nova prática pode assumir a supremacia sobre outras, neste caso, resultando no aumento de sua área de influencia. Com o método cartesiano, a partir do século XVII, ocorre uma verdadeira redefinição das relaçóes sujeito/objeto tanto no plano da ação como no plano do conhecimento. Nesta época, a razão "orientada desinteressadamente para a verdade e concebida sob o modo receptivo de uma apreensão empírica ou racional da essência das coisas, cede lugar, progressivamente, à razão e à ação instrumental" (FIGUEIREDO, 2008, p.13). Este processo teve grande influência no surgimento da chamada "psicologia 
científica" que surgiria na Alemanha quase dois séculos depois e que teve suas raízes estabelecidas nas pesquisas científicas laboratoriais, muitas delas com ênfase nos processos da experiência perceptiva. Estas experiências resultaram em ramificaçóes importantes, como a Gestalt, o comportamentalismo e, na área da pesquisa em música, na psicologia da música, na musicologia científica (Musikwissenschaft) e na etnomusicologia (MUGGLESTONE, 1981; MYERS, 1993; DEUTSCH, 1983; GREEN e BUTLER, 2002).

Um personagem-chave desta época foi Wilhelm Wundt, criador do primeiro laboratório de psicologia na cidade de Leipzig, em 1879, talvez um dos mais incompreendidos autores na literatura psicológica. Herdeiro da tradição filosófica da sua época, Wundt formulou em sua vasta produção, contabilizada em 53.735 páginas, uma verdadeira filosofia da psicologia (GOODWIN, 2005, p. 119). Nesta, assumiu o triplo desafio de criar uma psicologia experimental, uma psicologia social e uma metafísica científica. Esta última, centrada tanto nos processos cognitivos do conhecimento, quanto nos juízos de apreciação e valor (ARAÚJO, 2010). Infelizmente a dimensão filosófica da obra de Wundt tem sido esquecida em detrimento de seus estudos laboratoriais. Estes permitiram estabelecer uma relação entre mente e organismo, proporcionando uma base orgânica aos processos cognitivos e dando status à nova ciência que surgia (GOODWIN, 2005, p. 128). No entanto, sem uma adequada compreensão de seus escritos filosóficos, os problemas relativos à interpretação de sua psicologia não poderão ser satisfatoriamente resolvidos.

O Laboratório de Wundt era bastante precário para os padróes de hoje. Inicialmente apenas uma pequena sala, que aos poucos foi crescendo até se estabelecer como um instituto propriamente dito. Nestes laboratórios eram realizados experimentos que procuravam estabelecer medidas para a experiência sensorial e imaginária (por exemplo, imagens, sons, cores) e suas relaçóes com as funçôes mentais (percepção, vontade, desejo, etc.). O laboratório de Wundt foi totalmente destruído durante a segunda guerra mundial, mas desde sua inauguração serviu de modelo para outros que surgiram na Europa e nos Estados Unidos, como por exemplo, o laboratório da universidade de Harvard, reproduzidos abaixo em fotografias datadas de 1893. 


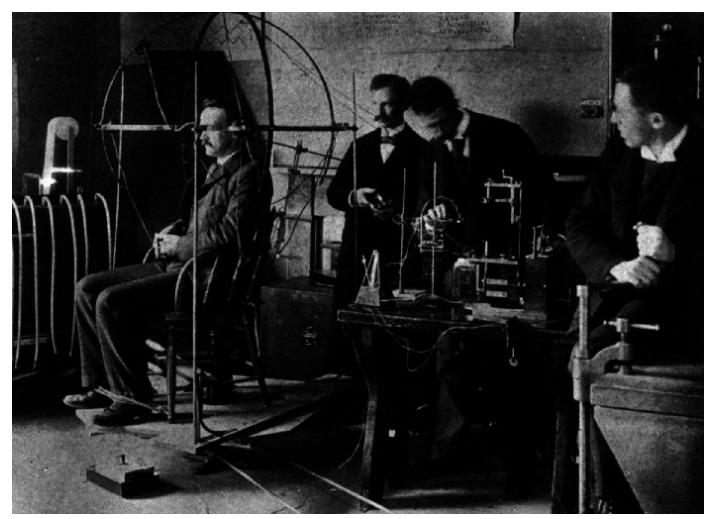

Figura 1: Experimentos sobre percepçáo auditiva no laboratório de psicologia da Universidade de Harvard. Fonte: Green (2000).

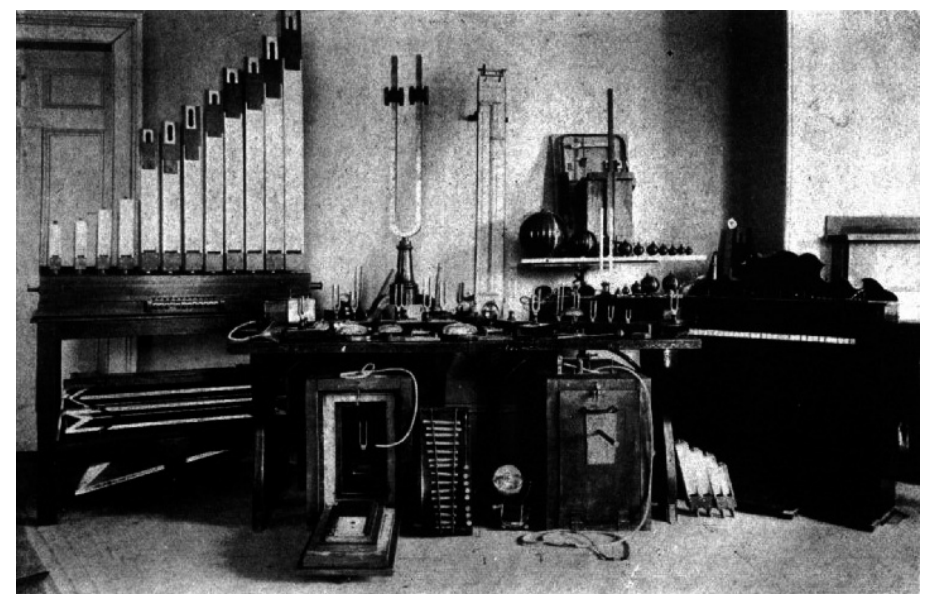

Figura 2: Instrumentos utilizados em experimentos sobre percepção auditiva no laboratório de psicologia da Universidade de Harvard. Fonte: Green (2000).

Outro importante centro de pesquisa sobre os fenômenos perceptivos visuais e sonoros da época foi o laboratório dirigido pelo filósofo, músico e psicólogo Carl Stumpf. Discípulo de Franz Brentano, Stumpf trouxe para a psicologia sua própria versão da fenomenologia e da consciência. Sua produção na área da percepção sonora inclui a Tonpsychologie, obra em dois volumes (publicados em 1883 e 1890, respectivamente) onde relata os resultados de seus experimentos e revisa conceitos da psicofísica, ciência voltada para a medição quantitativa tanto dos estímulos físicos como das sensaçôes que eles produzem. Para Green e Butler (2002, p. 246-71), o surgimento da Tonpsychologie como uma disciplina científica foi um momento decisivo na história da teoria musical. Stumpf também contribuiu para o desenvolvimento da dimensão institucional 
da psicologia. Além de fundar a escola de psicologia experimental de Berlim e o Berliner Phonogramm-Archiv, Stumpf foi amigo e correspondente de William James e teve um forte impacto na formação de Edmund Husserl, Max Wertheimer, Wolfgang Köhler e Kurt Koffka, criadores da psicologia Gestalt (BOWMAN, 2000). O contínuo interesse em psicologia dos tons musicais estimulou Stumpf a fundar em 1898 o jornal Beiträge zur Akustik und Musikwissenschaft (Contribuições à Acústica e à Musicologia) (MUGGLESTONE, 1981). Fruto das pesquisas realizadas neste este laboratório é o Systematik der Musikinstrumente, escrito por Hornbostel e Curt Sachs (1914), uma das obras que marcaram o surgimento da musicologia comparativa e da moderna organologia. Estes pesquisadores mudaram para sempre a pesquisa da percepçáo musical do ponto de vista cientifico e artístico.

No entanto, algumas pesquisas relevantes sobre percepçáo sonora antecederam o surgimento dos laboratórios de psicologia. Dentre estas, destacam-se o trabalho de dois pesquisadores: Helmholtz e Alexander Ellis. Segundo Blacking (1992, p. 301-2) estes autores utilizaram métodos experimentais para estudar a fisiologia da audição, os mecanismos da percepção, e a natureza de fenômenos acústicos como consonância, harmonia e escalas. Para eles, os métodos experimentais poderiam ser aplicados eficientemente para estudar a física da música, assim como para estudar a fisiologia e a psicologia da percepção sonora. Helmholtz publicou os resultados de suas pesquisas sobre a natureza da percepção sonora em 1863. Os temas abordados eram variados, estética, filosofia, psicologia, mas foi reconhecido principalmente por apresentar as bases matemáticas que davam suporte às suas teorias sobre visão, percepção do espaço, cor, e sons (VAUGHN, 1992, p. 464). Influenciado por Helmholtz, Ellis estudou a dimensão acústica das notas musicais e das escalas, desta forma criando a noção de music cents, que se tornou especialmente influente na musicologia comparativa. Analisando as escalas (sistemas de tom) de várias tradiçóes musicais não europeias, Ellis demonstrou que a diversidade dos sistemas não pode ser explicada por uma única lei física, como tinha sido defendido por autores anteriores (BLACKING, 1992, p. 301-5).

Portanto, embora a existência de pesquisas anteriores, pode-se situar as origens da musicologia comparativa, da et- 
nomusicologia e da psicologia da música nos laboratórios de psicologia experimental que passaram a surgir na Europa e Estados Unidos, mais precisamente na Alemanha, a partir de meados do século XIX. Estes laboratórios também promoveram o surgimento de elaboradas teorias sobre a percepçáo artística em suas várias dimensóes, no entanto, relativamente pouco destaque tem sido dado aos trabalhos pioneiros sobre percepçáo e cognição musical.

\section{SUBJETIVIDADE}

Embora a psicologia do século XIX buscasse no método científico um alicerce seguro para estabelecer suas raízes, no século XVII Galileu e Descartes já haviam introduzido dúvidas quanto à objetividade dos dados da percepçáo:

[...] a doutrina das qualidades primárias e secundárias adotada por Galileu e Descartes introduz uma suspeita exatamente em relação à confiança na percepçáo. $\mathrm{O}$ domínio da física restringe-se, com estes autores, ao que pode ser submetido à razáo matemática da geometria e da mecânica, medido e calculado. Objetos da ciência são apenas aqueles aspectos da realidade que podem ser reconhecidos pela razão como objetivo (qualidades primárias), enquanto que se exclui aquilo que é dado apenas e tão somente à sensibilidade. O puramente sensível é o ilusório, o transitório, a criação arbitrária do espírito (FIGUEIREDO, 2008, p. 16).

Também o materialismo histórico contribuiu para a desconfiança em relaçáo ao sensível e ao imediatamente observado, pois para esta corrente filosófica todo o conhecimento é mediado e construído. Desta foram rejeitando as metodologias que se apoiavam na introspecção e nas experiências sensoriais, perceptivas e afetivas, que não podiam ser quantificadas.

Mas, se a "psicologia científica" que surgiu na Alemanha crescia e ampliava sua esfera de influência, um movimento contrário e complementar se estabelecia em outras cidades da Europa. Em Viena e Paris, a emergência do conceito de inconsciente, inicialmente na medicina (neurologia e psiquiatria), instituiu novas teorias e práticas. Este conceito estava sendo gestado há muito tempo não apenas na psicologia, mas também na filosofia e na literatura: 
Por muito tempo, o conceito de inconsciente batia nas portas da psicologia, pedindo permissáo para entrar. A filosofia e a literatura frequentemente brincaram com ele, mas a ciência não encontrava, para ele, qualquer uso. A psicanálise apropriou-se do conceito, levou-o a sério e deu-lhe um conteúdo novo (FREUD, 1969a, p. 321).

O conceito de inconsciente traz em si um duplo desafio: de um lado reconhece a existência de uma região de desconhecimento na estrutura psíquica, de outro questiona o domínio único da razão e o governo de si mesmo apenas pelas ferramentas disponíveis na consciência. Já não se trata mais de identificar os processos pelos quais o sujeito conhece e atua no mundo. Aqui, trata-se do sujeito do inconsciente, marcado pelo desconhecimento dos processos mentais que existem nele mesmo, do desejo, e das influencias oriundas das camadas mais profundas da psique. Desta forma, localizando na profundidade destes processos subjetivos as fontes geratrizes dos nossos modos de viver e da criatividade artística.

Os vários movimentos artísticos (dadaísmo, expressionismo, surrealismo, entre outros) que surgem na Europa a partir do final do século XIX encontram fundamentação nos processos subjetivos. O romantismo já apontava para a valorização do indivíduo, para a liberdade de criação e expressão do misterioso, do exótico, do fantástico e da morte. De um lado a natureza como potência criadora e transformadora, de outro a valorização do sujeito e sua identidade, que não deve ser rompida pelos métodos objetivos das ciências naturais. Vejamos alguns exemplos. Durante certo período Richard Wagner e Friedrich Nietzsche foram muito amigos. Nesta época, Nietzsche utilizava a casa de campo do músico na Suíça. Buscava refúgio e inspiração para seus escritos, dentre eles o nascimento da tragédia no espírito da música, de 1871. Embora posteriormente negado pelo autor, percebe-se nestes escritos que Nietzsche fora profundamente influenciado pelo conceito wagneriano de drama musical como uma forma de arte total (Gesamtkunstwerk) onde a simbologia dos mitos é profundamente explorada no texto e na música, de forma a transmitir a intensidade de sentimento que o autor queria exprimir (NIETZSCHE, 2007, p. 82-83). Durante o verão de 1910, Mahler, profundamente deprimido, teve uma entrevista com Freud. Este revelou em uma carta nunca ter encontrado al- 
guém que tivesse compreendido a psicanálise assim tão rapidamente. Também na educaçáo musical é possível encontrar repercussóes desta nova psicologia, de Dalcroze a Willems e aos demais educadores musicais que valorizaram a subjetividade no ensino da música. Para estes, acessar as dimensóes mais profundas era um modo privilegiado de atribuir significados, produzir conhecimento, e motivar o ensino e a aprendizagem da música.

Theodor Reik, discípulo de Freud, estudou a vinculação entre os processos inconscientes e a percepção musical através da investigação da "haunting melody", um conceito introduzido por Freud:

Conheço um jovem que se sentiu durante algum tempo realmente perseguido pela melodia (aliás, uma melodia maravilhosa) da canção de Páris [Offenbach] La belle Hélène, até que, em sua análise, ele teve sua atenção voltada para uma rivalidade em torno de sua pessoa e em benefício seu, uma rivalidade entre uma 'Ida' e uma 'Helena'. Se então as coisas que vêm à mente de uma pessoa assim tão livremente, são de tal maneira determinadas e formam parte de um todo inter-relacionado, sem dúvida estamos agindo acertadamente ao concluir que não podem ser menos determinadas aquelas coisas que lhe acodem à mente com apenas um vínculo - ou seja, o vínculo delas com a ideia que serve como seu ponto de partida. A investigaçáo realmente mostra que, afora o vínculo que lhe fornecemos com a ideia inicial, essas associaçôes são dependentes também de grupos de ideias e de interesses intensamente emocionais, os 'complexos', cuja participação não é conhecida no momento - ou seja, é inconsciente. A ocorrência de ideias com vínculos dessa espécie tem sido objeto de pesquisas experimentais muito elucidativas que desempenharam um papel notável na história da psicanálise (FREUD, 1976b, p. 70).

Reik acreditava que determinadas melodias teriam a capacidade de acessar emoçóes de forma mais intensa que as palavras. Eram como vozes do desconhecido dando passagem a mensagens secretas: "A haunting melody substitui a magia das palavras pela onipotência do som” (REIK, 1953, p. 167). Para Reik, o material inconsciente poderia emergir com maior facilidade com melodias do que com pensamentos, por expressar melhor as emoçóes e sentimentos desconhecidos. As- 
sim, sugeriu que a música poderia interagir com a psicanálise de maneira eficaz, ajudando a resolver conflitos reprimidos.

A influência da psicanálise e de outras teorias psicológicas pode ser mais fortemente sentida nas artes plásticas e na literatura; do manifesto surrealista do poeta e psiquiatra francês André Breton à produção fantástica de Salvador Dali. Admirador da psicanálise e leitor de Freud e Lacan, Dali não só se identificava com sintomas de histeria, narcisismo e paranóia como também trouxe para suas próprias obras o método psicanalítico da associaçáo livre, através do denominado "método crítico-paranóico" (RIVERA, 2005). O professor e crítico de arte Anton Ehrenzweig (1967) utilizou elementos da Gestalt e da psicanálise para analisar a psicologia da criatividade artística. Focalizando principalmente nas artes visuais, mas também na música, Ehrenzweig mostrou que, além da consciência e do intelecto, a criança e o artista criativo utilizam o processo intuitivo e inconsciente para dar forma a sua visão do mundo. Mais recentemente, após o final da segunda guerra mundial, a musicoterapia surge no cenário cientifico e acadêmico e recebe toda a influência da psicologia. Desde então tem experimentado um crescimento contínuo.

As ciências contemporâneas têm demonstrado a importância de considerar a grande complexidade do real e a densa trama de relaçóes que revestem os fenômenos observados. Não obstante os grandes esforços em estabelecer padróes e técnicas, causas e efeitos, leis e metodologias, a música, assim como todas as artes, possui uma dimensão subjetiva. Embora a partitura, ou o registro sonoro, sejam dados objetivos (res extensa), quando o evento musical adquire vida pela interaçáo com o ouvinte criativo (res cogitans) ele é vinculado a elementos extremamente saturados de significados, de conotaçóes culturais, de disposiçóes emocionais e cognitivas.

\section{PSICOTÉCNICAS}

Um dos grandes temas da psicologia da música é definir, identificar e quantificar inteligência musical. A utilização sistemática de métodos e técnicas quantitativas para a avaliação e resolução de problemas já estava plenamente estabelecida ao final da Segunda Guerra Mundial. Aqui não se trata mais do sujeito da razão, tampouco das suas subjetividades, discu- 
tidos nos dois itens anteriores, mas do sujeito das representaçôes sociais, da estatística, da distribuiçấo da curva normal. Aqui o espelho que revela o indivíduo é o das instituiçôes sociais, pois é através das diferentes instituiçôes, como família, educação, trabalho, que o sujeito é pensado, observado, classificado e organizado hierarquicamente, muitas vezes através de treinamentos, qualificaçóes e capacitaçôes. Aqui a razáo instrumental encontra plena expressão na forma de psicologias aplicadas e tecnologias da subjetividade: classificaçôes, critérios, escalas de comparação, testes vocacionais, teste QI, testes de aptidáo, etc.

Os primeiros estudos científicos sobre inteligência foram realizados sobretudo por três autores: Esquirol que em 1838 associou níveis de atraso mental com níveis de fluência verbal; Francis Galton, primo de Charles Darwin e criador da "eugenia", que tentou sem sucesso relacionar inteligência com características mensuráveis como diâmetro da cabeça, velocidade dos reflexos, acuidade visual; e Alfred Binet que, em 1905, publicou uma escala métrica de inteligência a partir de estudos desenvolvidos com Théodore Simon. O termo QI surge mais tarde, com a publicação de uma versão aprimorada dos testes de Binet-Simon, na qual Lewis Terman introduz o conceito de quociente de inteligência, representando a idade mental multiplicada por 100 e dividida pela idade cronológica. Desde estes primeiros testes, a psicologia procura compreender a natureza da inteligência, o que pode ser constatado na multiplicidade de visóes e na imensa quantidade de publicaçóes a respeito desse tema.

Modernamente, a concepção psicométrica de inteligência está sustentada na análise fatorial, ou seja, na análise pormenorizada de cada parte (fator) de um todo. Para Primi, a análise fatorial "baseia-se nas diferenças individuais reveladas por uma centena de testes criados para avaliar as capacidades cognitivas. O propósito da análise fatorial é identificar os subgrupos de testes que avaliam uma mesma capacidade cognitiva" (PRIMI, 2003, p. 68). A lógica deste procedimento é que, se dois testes requerem uma mesma capacidade cognitiva, entáo aquelas pessoas que apresentarem esta capacidade desenvolvida tendem a conseguir escores altos nos dois testes simultaneamente. Ao contrário, aquelas pessoas com menor capacidade tendem a apresentar escores baixos nos dois tes- 
3. Inteligência Fluida (Gf); Inteligência Cristalizada (Gc); Conhecimento Quantitativo (Gq); Leitura e Escrita (Grw); Memória de Curto Prazo (Gsm); Processamento Visual; Processamento Auditivo (Ga); Capacidade e Armazenamento e Recuperação da Memória Longo Prazo (Glr); Velocidade de Processamento (Gs); Rapidez de Decisão (Gt) (PRIMI, 2003). tes simultaneamente. Assim, como se deseja descobrir quais são as capacidades que compóem a inteligência, percorre-se o caminho inverso, isto é, aplica-se uma bateria de testes que inclui as diversas capacidades intelectuais, emprega-se a análise fatorial para agrupar os resultados e, por fim, analisam-se estes grupos buscando quais são as capacidades comuns envolvidas na resolução dos testes.

$\mathrm{Na}$ primeira metade do século passado os estudos sobre inteligência debatiam a estrutura (quantidade) e a definição (qualidade) das capacidades intelectuais. Existiam duas posiçóes distintas: a de Spearman (1927), que acreditava na existência de um fator geral $(G)$ que expressava toda a atividade intelectual, e a de Thurstone (1938), denominada teoria das aptidóes primárias, que não aceitava a existência de um fator geral, mas sim de um conjunto de habilidades básicas ou primárias (PASQUALI, 2003). Na segunda metade do século passado esta concepção polarizada evoluiu para um modelo integrado hierárquico, conhecido como teoria de Cattell, Horn e Carroll (CHC) das habilidades cognitivas (McGREW, 1997). Este modelo consiste numa visão multidimensional com dez fatores ${ }^{3}$ ligados a áreas amplas do funcionamento cognitivo. Estas capacidades estariam associadas aos domínios da linguagem, raciocínio, memória, percepção visual, recepçáo auditiva, produçáo de ideias, velocidade cognitiva, conhecimento e rendimento acadêmico.

Mas como medir inteligência musical? A ideia de uma inteligência musical não é recente. Talvez o organista e crítico de música norte americano William Mathews tenha sido o primeiro a publicar um trabalho científico sobre inteligência musical. Como o próprio autor ressalta, trata-se de uma área nova, sendo seu objetivo principal levar o aluno a uma "consciência da música como música e não apenas como execução, canto ou teoria (...), ou seja, com a observação de fraseologia musical, da arte de ouvir e entender o discurso musical" (MATHEWS, 1881, p. 5).

Este livro, no entanto, não apresenta um teste avaliativo. Carl Seashore (1919) foi provavelmente o primeiro a desenvolver um teste de habilidade musical propriamente dito. Para Humphreys (1998), Seashore foi largamente influenciado pelas ideias de James McKeen Cattell que, desde seu retorno da Europa, em 1989, conduzia amplos estudos sobre testes de 
inteligência e, em especial, sobre percepção musical. Cattell também conduziu estudos estatísticos longitudinais testando a hipótese de que as habilidades musicais estariam diretamente ligadas ao desempenho escolar (HUMPHREYS, 1998). Seashore, que também se interessava pelas artes plásticas, trabalhou em conjunto com o Norman Meier na elaboração de um teste mais amplo conhecido como Meier-Seashore art judgment test. $\mathrm{Na}$ Inglaterra, os primeiros estudos e testes, desenvolvidos por Enthleon Tittlr e Lilian Smith em 1934 e 1938, respectivamente, foram destinados a avaliar inteligência musical em escolas superiores. Mas foi possivelmente Paul Farnsworth quem mais estudou temas que se localizam na interface música e psicologia. Dentre sua enorme produção, que se estende por mais de meio século e soma mais de uma centena de livros, artigos e revisóes, um livro se destaca: psicologia social da música (1958). Este livro trazia seus grandes interesses em foco e articulava as dimensóes biológicas, sociais e culturais da música.

Particularmente relevantes para a educação musical são os trabalhos de Gordon e Karma sobre avaliaçáo e desenvolvimento da aptidáo musical. Gordon estabeleceu dados estatísticos a partir de amplos estudos longitudinais em grandes populaçóes, possibilitando uma melhor compreensão dos fenômenos relacionados à aptidão musical (GORDON, 1979, 1987). Dentre estes, o reconhecimento da existência de uma janela de desenvolvimento musical privilegiado que perdura até cerca dos nove anos, quando se inicia uma fase de estabilizaçáo. Certamente o reconhecimento precoce das aptidōes musicais pode fornecer elementos para melhorar a qualidade dos processos de ensino e aprendizagem da música. A construçáo de modelos teóricos, bem como a elaboração e validação de construtos, testes e medidas relacionadas à aptidão musical tem sido estudada por Kai Karma por mais de quatro décadas. No entanto, segundo o autor, ainda apresentam grandes desafios teóricos e práticos ao pesquisador: "em princípio, a determinação da validade de uma medida é um processo interminável; cada informaçáo nova sobre um teste pode adicionar uma nova peça ao quebra-cabeça" (KARMA, 2007, p. 89). Para Karma os dados empíricos contribuem para progressivamente aumentar o conhecimento sobre a validade das medidas obtidas. 
A teoria das inteligências múltiplas, de Howard Gardner (1983), segue uma lógica semelhante à teoria de Cattell, Horn e Carroll (McGREW, 1997), descrita anteriormente, e se caracteriza pelo desmembramento da inteligência em sete habilidades: linguística, lógico-matemática, espacial, cinestésica, interpessoal, intrapessoal e musical. Esta teoria permitiu não apenas uma descrição e análise das características gerais desta modalidade de inteligência, mas também uma verdadeira mudança de paradigma na educação musical. Ao reconhecer as diferentes habilidades e talentos dos alunos, a escola pode estimular a abordagem multidimensional dos conteúdos, desta forma estimulando em seus alunos o desenvolvimento de um senso de realizaçáo e autoconfiança. Resta lembrar que embora a relevante contribuição que os inúmeros testes de aptidão trouxeram para o desenvolvimento de planos e estratégias pedagógicas para sala de aula, é preciso lembrar que os professores de música devem utilizá-los com cuidado quando se trata de critérios de avaliaçãoo e seleçáo (FERNANDES, 2005, p. 372).

Assim, chegamos ao século XXI com uma grande diversidade de abordagens e dispersão dos conceitos sobre inteligência musical. Recentemente Jeanne Bamberger (1991) investigou o desenvolvimento da inteligência musical com base na psicologia cognitiva, mas adotando uma perspectiva interdisciplinar. Este trabalho, construído a partir da análise de crianças e adultos em momentos da aprendizagem espontânea, buscava determinar o grau de percepção da expressividade musical através da escuta de trechos distintos de música com diferentes níveis de expressividade. Simha Arom (1994) discutiu a inteligência musical a partir de uma perspectiva etnomusicológica. David Cope (2005) adotou como fundamento teórico a psicologia cognitiva para investigar a possibilidade de criar programas de computador que reproduzam a criatividade musical. Para isso, Cope criou uma série de modelos experimentais que, segundo ele, delinearia as principais características da criatividade musical. Cope acredita que a criatividade pode ser modelada através de um processo por ele chamado de "associação indutiva", o qual teria a capacidade de produzir música criativamente. Montello (2002) propôs a utilização da inteligência musical como um caminho para a cura, a criatividade e a completude. Neste ponto é importante 
direcionar o leitor para autores como Cuddy (1992, 2009); Deutsch (1983); Hodges (1996); Hodges e Sebald (2011), que possuem um extenso trabalho na área e podem fornecer um contraponto às posiçóes teóricas que incorporam mais intensamente a dimensáo subjetiva em suas análises.

No Brasil, a partir das duas últimas décadas, edificaram-se grupos de pesquisa e programas acadêmicos que articulam as áreas de psicologia e música. Infelizmente a dimensão e a natureza deste texto náo permitem destacar a produção dos muitos autores e pesquisas relevantes em andamento no Brasil. Esta produçáo pode ser acessada através de inúmeros trabalhos oriundos de encontros, congressos e demais publicaçôes promovidas por universidades e instituiçôes como a Associação Brasileira de Educação Musical (ABEM), a Associação Nacional de Pesquisa e Pós-Graduação em Música (ANPPOM) e os Simpósios de Cogniçáo e Artes Musicais (SIMCAM).

\section{CONSIDERAÇÓES FINAIS}

A subdivisão em três eixos, razão, subjetividade e psicotécnicas, oferece um horizonte favorável à análise da produçáo científica que se desenvolveu em torno da interface psicologia e música. No primeiro caso, constatou-se a possibilidade de estabelecer as origens da musicologia comparativa, da etnomusicologia e da psicologia da música nos laboratórios de psicologia experimental que passaram a surgir nos Estados Unidos e Europa, no século passado. Estes laboratórios também foram o nascedouro de elaboradas teorias sobre a percepção artística, no entanto, enquanto esta origem é amplamente reconhecida e estudada em outras áreas, insuficiente atenção tem sido dada aos trabalhos pioneiros na área da percepçáo e cognição musical.

No segundo caso, constatou-se que a influência da psicanálise pode ser mais fortemente sentida nas artes plásticas e na literatura, e que teorias e conceitos oriundos da Gestalt, da psicanálise e de outras teorias psicológicas centradas na subjetividade têm se mostrado úteis na análise da obra de arte e da criatividade artística. Pois, como vimos, além da consciência e do intelecto, a criança ou o artista criativo utilizam processos subjetivos na construção de sua visão do mundo. Não obstan- 
te o empenho em estabelecer padróes e técnicas, causas e efeitos, leis e metodologias, a música está vinculada a elementos saturados de significados, de conotaçôes culturais, de disposiçôes emocionais e cognitivas. Mais recentemente, a musicoterapia ganhou espaço no cenário cientifico e acadêmico e desde então tem experimentado um crescimento contínuo.

No terceiro caso, embora o avanço ocorrido nas últimas décadas na área em estudo, fruto de novas teorias, métodos e tecnologias, concluiu-se que definir em que consiste, como evoluiu, como avaliar e aprimorar a inteligência musical são questôes ainda em aberto. Ainda que seja consenso a concepção de que o processo evolutivo humano está refletido nas habilidades de raciocinar, testar ideias, comunicar, e planejar o futuro, existem outras habilidades fundamentais para nossa espécie, dentre elas a capacidade de lidar com símbolos, representar e atuar criativamente. Todas estas diretamente ligadas às diversas dimensôes de atuação da música. As respostas que vão surgindo podem ser agrupadas em diferentes posiçóes no continuum mente-cérebro. Desta forma, os testes de inteligência musical têm se mostrado particularmente difíceis de serem validados do ponto de vista psicométrico. Como vimos, embora as relevantes contribuiçôes que os inúmeros testes de aptidáo trouxeram para a prática do educador musical, é preciso lembrar que estes devem ser utilizados com cuidado quando se trata do estabelecimento de critérios de avaliaçáo e seleção.

Um longo caminho foi percorrido desde os primeiros laboratórios criados no século XIX às modernas tecnologias disponíveis aos pesquisadores atuais. Nas últimas décadas as neurociências têm fertilizado, renovado e multiplicado os conhecimentos sobre a musicalidade humana. São muitos os temas de interesse, do desenvolvimento da musicalidade na vida intrauterina aos mapas neurais de respostas à música, das origens da música às vinculações entre o pensar e o sentir. $\mathrm{O}$ futuro pode nos reservar resultados surpreendentes. 


\section{REFERÊNCIAS BIBLIOGRÁFICAS}

ARAÚJO, S. F. O projeto de uma psicologia cientifica em Wilhelm Wundt: uma nova interpretação. Juiz de Fora: Editora da UFJF, 2010.

AROM, S. Intelligence in traditional music. In: KHALFA, J. (Ed.). What is intelligence? Cambridge: Cambridge University Press, 1994. p. 137-160.

BAMBERGER, J. S. The mind behind the musical ear: how children develop musical intelligence. Cambridge: Harvard University Press, 1991.

BLACKING, John. How musical is man? Seattle: University of Washington Press, 1973.

. The biology of music making. In MYERS, H. (Ed.). Ethnomusicology: an introduction. New York: W. W. Norton \& Co, 1992. p. 301-314.

BOWMAN, C.; BROWNELL, P. Prelude to contemporary gestalt therapy. Gestalt, v. 4, n. 3, Set., 2000. Disponível em <http://www.g-gej.org/4-3/prelude.html . Acesso em 11 Set. 2012.

CAMBAÚVA, L.; SILVA, L.; FERREIRA, W. Reflexões sobre o estudo da história da psicologia. Estudos de psicologia, Natal, v. 3, n. 2, Jul., p. 207-227. 1998.

COPE, D. Computer models of musical creativity. Cambridge: MIT Press, 2005.

CUDDY, Lola; UPITIS, R. Percepção auditiva. In: COLWELL, R. (Ed.). Handbook of research on music teaching and learning. New York: Schirmer Books, 1992. p. 333-343.

CUDDY, Lola. Development of music perception and cognition research: an autobiographical account from a canadian perspective. Psychomusicology: Music, Mind \& Brain, v. 20, n. 1, p. 43-51, 2009. Disponível em <http://ojs.vre.upei.ca/index.php/psychomusicology/index>. Acesso em 11 Set. 2012.

DEUTSCH, Diana (Ed). The psychology of music. San Diego: Academic Press, 1983. 
EHRENZWEIG, A. The hidden order of art. London: Phoenix Press, 1967.

ELLIS, A. On the musical scales of various nations. Journal of the society of arts, Londres, v. 33, p. 485-527, 1885.

FARNSWORTH, P. The social psychology of music. New York: The Dryden Press, 1958.

FERNANDES, José Nunes. A inteligência e a criatividade musicais na escola brasileira. In: SIMPÓSIO INTERNACIONAL DE COGNIÇÃO E ARTES MUSICAIS, 1, 2005, Anais. Curitiba: UFPR. 2005. p. 370-379.

FIGUEIREDO, L. Matrizes do pensamento psicológico. 18. ed. Petrópolis: Editora Vozes, 2008.

FREUD, S. Esboço de psicanálise. Tradução de J. Salomão. Rio de Janeiro: Imago, 1976a.

. Conferências introdutórias sobre psicanálise. Tradução de J. Salomão. Rio de Janeiro: Imago, $1976 b$.

GARDNER, H. Frames of mind. New York: Basic Books Inc, 1983.

GOODWIN, C. História da psicologia moderna. Tradução de M. Rosas. 13. ed. São Paulo: Cultrix, 2005.

GORDON, E. Primary measures of music audiation. Chicago: GIA Publications, 1979.

. The nature, description, measurement and evaluation of musical aptitudes. Chicago: GIA Publications, 1987.

GREEN, B.; BUTLER, D. From acoustics to tonpsychologie. In CHRISTENSEN, T. (Ed.). Cambridge History of Western Music Theory. Cambridge: Cambridge University Press, 2002, p. 246-271.

GREEN, Christopher D. Psychological laboratory of Harvard University. In: Classics in the history of psychology: an internet resource, York University, Toronto. 2000. Disponível em <http://psychclassics.yorku.ca/Munster/Lab>. Acesso 11 Set. 2012.

HELMHOLTZ, Hermann. Die Lehre von den Tonempfindungen: physiologische Grundlage für die Theorie der Musik. Brunswick: Vieweg-Verlag, 1863. Disponível em <http:// 
archive.org/stream/dielehrevondento028665mbp\#page/n7/ mode/2up>. Acesso em 11 Set. 2012.

HODGES, D. (Ed). Handbook of music psychology. 2. ed. San Antonio: IMR Press. 1996.

HODGES, D.; SEBALD, D. Music in the human experience: an introduction to psychology of music. New York: Routledge, 2011.

HORNBOSTEL, E. M. von; SACHS, C. Systematik der Musikinstrumente: ein Versuch. Zeitschrift für Ethnologie, Berlin, v. 46, p. 553-590, 1914.

HUMPHREYS, J. T. Musical aptitude testing: from James McKeen Cattell to Carl Emil Seashore. Research studies in music education, v. 10, p. 42-53, 1998. Disponível em <http:// www.public.asu.edu/ aajth/Personal/Mus\%20Apt\%20Test--RSME.PDF>. Acesso em 11 Set. 2012.

KARMA, K. Musical aptitude definition and measure validation: ecological validity can endanger the construct validity of musical aptitude tests. Psychomusicology: A Journal of Research in Music Cognition, v. 19, n. 2, p. 79-90, 2007.

KHALFA, J. What is intelligence? Cambridge: Cambridge University Press, 1994.

MCGREW, K. Analysis of the major intelligence batteries according to a comprehensive Gf-Gc framework. In: FLANAGAN, P.; GENSHAFT, J.; HARRISON, P., Contemporary intellectual assessment: theories, tests and issues. New York: Guilford Press, 1997. p. 131-150.

MATHEWS, S. How to understand music: a concise course in musical intelligence and taste: to which is added a pronouncing dictionary and condensed encyclopedia of musical terms and information. Chicago: Lyon Publishers, 1881. Disponível em <http://ia700500.us.archive.org/15/items/howtounderstandm00math/howtounderstandm00math.pdf $>$. Acesso em 11 Set. 2012.

MONTELLO, L. Essential musical intelligence: using music as your path to healing, creativity, and radiant wholeness. Wheaton: Quest Books, 2002.

MUGGLESTONE, E. Guido Adler's the scope, method, and aim of musicology (1885): an english translation with 
an historico-analytical commentary. Yearbook for Traditional Music, v. 13, p. 1-21, 1981.

MYERS, H. (Ed.). Ethnomusicology: historical and regional studies. New York: W. W. Norton \& Co, 1993.

NIETZSCHE, F. O caso Wagner. São Paulo: Editora Escala, 2007.

PASQUALI, L. Psicometria: teoria dos testes na psicologia e na educação. Petrópolis: Vozes, 2003.

PRIMI, R. Inteligência: avanços nos modelos teóricos e nos instrumentos de medida. Avaliação Psicológica, Ribeirão Preto, v. 2, p. 67-77, 2003.

REIK, T. The haunting melody: psychoanalytic experiences in life and music. New York: Farrar, Straus and Young, 1953.

RIVERA, T. Arte e psicanálise. 2. ed. Rio de Janeiro: Jorge Zahar, 2005.

SEASHORE, C. E. The psychology of musical talent. New York: Silver, Burdett and Company, 1919.

SPEARMAN, C. The abilities of man: their nature and measurement. New York: The Macmillan Company, 1927.

THURSTONE, L. L. Primary mental abilities. Chicago: University of Chicago Press, 1938.

VAUGHN, Kathryn. Pitch measurement. In MYERS, H. (Ed.). Ethnomusicology: an introduction. New York: W. W. Norton \& Co, 1992. p. 462-468.

WARRAK, John. Romantic. In SADIE, S. (Ed.). The New Grove Dictionary of Music and Musicians. London: MacMillan, v. 16, 1980. p.141-144. 